\title{
Why Dolphins are not Aquatic Apes
}

\author{
Louise Barrett $^{1 *}$ and Bernd Würsig ${ }^{2}$ \\ ${ }^{1}$ University of Lethbridge \\ ${ }^{2}$ Texas A\&M University at Galveston \\ *Corresponding author (Email: louise.barrett@uleth.ca)
}

Citation - Barrett, L., Würsig, B. (2014). Why dolphins are not aquatic apes. Animal Behavior and Cognition, 1(1), 1-18. doi: 10.12966/abc.02.01.2014

\begin{abstract}
The Social Brain (or Social Intelligence) hypothesis is a very influential theory that ties brain size and, by extension, cognitive ability to the demands of obligate and intense sociality. Initially developed to explain primate brain size evolution, the Social Brain hypothesis has since been applied to a diverse array of other social taxa, both mammalian and avian; its origins as a primate-based hypothesis (especially as articulated by Humphrey, 1976), however, mean that it retains a heavily anthropocentric tinge. This colors the way in which other species are viewed, and their cognitive abilities tested, despite fundamental differences in many aspects of bodily morphology, brain anatomy and behavior. The delphinids are a case in point and, in this review, we demonstrate how the anthropocentric origins of the Social Brain hypothesis have pushed us toward a view of the delphinids as a species of 'aquatic ape'. We suggest that a more ecological, embodied/embedded, view of dolphin behavior and psychology undercuts such a view, and will provide a more satisfactory assessment of the natural intelligence the delphinids display.
\end{abstract}

Keywords - Social Brain hypothesis, Delphinids, Primates, Cognition, Behavior, Psychology

Tracing the history of ideas, scientific or otherwise, is always interesting, and the social intelligence hypothesis is no exception. This may cause your heart to sink already; after all, the history and development of this particular idea has been presented many times before (e.g., Byrne \& Whiten, 1988; Whiten \& Byrne 1997; Cheney \& Seyfarth, 2008; Dunbar, 1998; Shultz \& Dunbar, 2007). In the context of our specific aim here, however, we consider a historical perspective to be crucial because, in our view at least, one of the key papers in the field - Humphrey's (1976) "The social function of intellect" - set things on a particular trajectory that, ultimately, has been somewhat self-defeating. More specifically, Humphrey defined and conceptualized social intelligence in heavily anthropocentric terms, the legacy of which is still felt today. This has hampered our attempts to understand why sociality is linked to enlarged brain size across a broad range of taxa, including the taxonomic order of cetaceans, and in particular, the delphinids and sperm whales.

In what follows, we do not attempt to make a case for the social intelligence of primates and cetaceans. This has been done elsewhere (e.g., Dunbar \& Shultz 2007; Silk 2007; Cheney \& Seyfarth 1990, 2008; Rendell \& Whitehead 2001; Wells 2003; Marino et al. 2008; Whitehead \& Lusseau, 2012). Instead, we highlight certain theoretical and conceptual issues that suggest why the social intelligence hypothesis needs some tweaking, and why this move will give cetaceans (and other non-primate species) their due with respect to understanding how and why their way of encountering the world gives rise to flexible, adaptive behavior. 


\section{Barking up the wrong tree?}

At first glance, the suggestion that Humphrey's initial thoughts on social intelligence and the brain have hampered our subsequent research efforts may seem outrageous given the proliferation of papers over the last 15-20 years, especially those by Robin Dunbar, who presented the first quantitative analyses testing the "Social Brain hypothesis" (e.g., Dunbar 1992, 1993, 1995, 1998; Dunbar \& Bever, 1998; Dunbar \& Shultz, 2007a,b, 2010; Kudo \& Dunbar, 2001; Shultz \& Dunbar, 2007a,b, 2010; Sutcliffe, Dunbar, Binder, \& Arrow, 2012; see also work by, Brothers, 1990; Brothers \& Ring, 1993; Barton, 1996, 1998; Reader \& Laland, 2002; Lefebvre, Reader, \& Sol, 2004). Not only has a robust relationship been found between primate sociality and the size of the neocortex, but other taxa also show a relationship between brain size and sociality, suggesting that the effect is general and not exclusive to the primates (see Dunbar \& Shultz, 2007a,b for reviews; Shultz \& Dunbar, 2010). The nature of the relationship in other terrestrial taxa, however, is often distinctively different to that among the primates, with pair-bonding emerging as the key correlate of enlarged brain size (Dunbar \& Shultz, 2007a,b). This has led to a reconfiguring of the social intelligence/social brain hypothesis to accommodate these findings. Testing for a relationship between group size and relative brain size (specifically the size of the neocortex) among the primates was predicated on the assumption that tracking a large number of dyadic relationships in a permanent social group generated a significant cognitive burden. This quantitative demand was accompanied by a qualitative component whereby animals were assumed to have a conceptual understanding of triadic relationships and abstract social bonds (Dunbar, 1998). The discovery that pair-bonded species have the largest relative brain sizes in ungulates and birds has reversed the interpretation so that it is primarily the quality of relationships, and not their quantity, that is important (Dunbar \& Shultz, 2007a,b, 2010). McLean, Barrickman, Johnson, and Wall (2009) have recently shown, however, that there is no relationship between pair-bonding and brain size among the lemurs, suggesting that the significance of pair-bonding may not be generalized across all taxa.

Dunbar and Shultz $(2007 a, b)$ argue that the high costs of choosing a poor quality mate and the need for close behavioral coordination account for the cognitive burden of pair-bonding. For primates, the finding that both pair-bonded and other kinds of mating system are associated with larger brain size is suggested to occur because primates have generalized the intense nature of pair-bonds across all group members. Consequently, the challenge now is to discover whether the mate choice decisions of pairbonded species require greater cognitive skills compared to other species, and to test whether close behavioral coordination requires complex cognitive strategies as opposed to, say, hormonally-mediated behavioral strategies (e.g., Insel \& Young, 2000) or the kinds of simple rules of thumb that characterize the complex feats of coordination shown by bird flocks and fish schools (e.g., Ballerini et al., 2008).

There are also alternative suggestions that need to be factored in: one argument is that cooperative breeding, rather than pair-bonding per se, has selected for greater cognitive abilities among certain groups of primates, particularly the callitrichids (Burkart \& van Schaik, 2010; Snowdon, 2001) and that this may also apply to members of the canid family (Burkart \& van Schaik, 2010); like MacLean et al.'s (2009) lemur work, this research suggests that 'social intelligence' may not be all of a piece, even within the primate order. Similarly, Hrdy (2009) has argued that cooperative breeding helps explain the cognitive differences between humans and great apes. A final, related, challenge is to show that evolutionary increases in the size of those parts of the brain that have multiple functions can be traced causally to sociality in the manner suggested (Healy \& Rowe, 2007; see also Healy \& Rowe, 2013 for a related argument concerning causality in brain size evolution).

In other words, although the social intelligence hypothesis has departed radically from its earliest beginnings (as most hypotheses do), the notion that sociality requires a specific form of complex cognitive assessment, and that this is underpinned by enlarged brain size, has remained at its core. There is also the assumption that the same factor (pair bonding) can explain the brain size-sociality relationship across all species (or, at least, there is very little explicit recognition in most analyses that a species' evolutionary history, ecology and morphology have a role to play). The result is that, as currently conceived, the social brain/social intelligence hypothesis argues that pair-bonding must be more 
cognitively complex than we have supposed, and the fault lies with our inadequate understanding of the nature of 'bonds' and not with the central hypothesis itself (Dunbar \& Shultz, 2007b, 2010).

\section{Why history matters}

It is at this point that an assessment of history comes in handy, for our argument is that, while the early papers of Chance and Mead (1953) and Jolly (1966) were concerned specifically with the reasons why non-human primates would need big brains, Humphrey's (1976) paper is significantly more anthropocentric in nature, and more focused on the specific form of 'intellect' for which sociality would select. Humphrey's argument is framed such that selection is argued to have produced a particular kind of complex cognitive architecture, underpinned by large brains, and one that is reflective of some distinctively primate (if not utterly human) concerns. This, in turn, has led to the inconsistencies and problematic elements recently identified by, most notably, Healy and Rowe (2007) and Holekamp (2007).

We should be clear that a number of Humphrey's (1976) arguments are made in the same vein as the earlier papers by Chance and Mead (1953) and Jolly (1966). Humphrey (1976) notes, for example, that socially housed monkeys do not lack for intellectual stimulation because social life is inherently stimulating. He then combines this with his observations that mountain gorillas do not seem to experience ecological challenges any greater than those experienced by less neurally well endowed species, leading to the conclusion that the selective pressure to enlarge brain size must indeed have come from the social domain. More specifically, Humphrey (1976) argues that primates need to be "social gamesmen" (p.309), akin to human chess players; in order to thrive, they need both to preserve the group's overall structure while simultaneously "exploiting and out-manoeuvring others" (p. 309). All primates need, therefore, to be "calculating beings," capable of a "special form of forward planning" (p.309). This allows them to predict what another animal is likely to do and ensure that one's own goals are not thwarted by the actions of another. In such a situation, Humphrey argues, "“social skill' goes hand in hand with intellect" (p.309). Humphrey characterizes this kind of intellect as 'creative' in contra-distinction to 'practical' intelligence, such as that needed to forage efficiently and successfully. Indeed, he argues that, provided the right kind of social background is in place, the practical skills needed to subsist effectively can be learned by simple associative processes. It is the social world alone that generates the pressure to evolve a more 'creative' form of intelligence. In this way, a large brain becomes equated with a particular kind of complex, cognitive skill: namely, the ability to make a prospective assessment of another's future actions which, even though not stated explicitly, is essentially the ability to construct 'detached' representations of the world (i.e., those not tied to an immediately present stimulus: see , Gärdenfors 1995). In other words, in order to respond to the dynamic contingencies generated by other animate beings, primates require a specific psychological insight into the minds and actions of other animals.

More strongly anthropocentric arguments follow from this, as Humphrey (1976) goes on to suggest that these socio-cognitive skills emerged within the context of a stable society that functioned as a kind of "polytechnic school" (p.310). In such a context, youngsters would be freed from the demands of taking care of themselves, and so could "explore and experiment" (p.310). In addition, via contact with older more experienced individuals, they could learn by imitation all that they needed to function in society. In these passages, Humphrey keeps things fairly loose, and it is not always clear whether he is referring to all primate species, just some of them, or humans alone (as, for example, when he suggests that young can learn "in some cases, from more formal lessons," p.310). It should be apparent, however, that the picture painted by Humphrey bears a much closer resemblance to human society than monkey or ape societies (let alone those of other species). Indeed, it often seems to be simply a picture of human society projected back in time.

Another telling detail is when Humphrey notes that, if animals were to spend large amounts of the day engaged in creative but nonetheless "unproductive" (p.311) socializing, this would require that, when they did finally get down to the business of productively feeding themselves, the technological advances provided by an improved intelligence would need to be sufficiently well developed to compensate. Following this reasoning, he then notes that "the open sea is an environment where technical knowledge 
can bring little benefit and thus complex societies - and high intelligence - are contra-indicated (dolphins and whales provide, maybe, a remarkable and unexplained exception)" (p.311, italics added).

Once again, the anthropocentric bias is clear (why else would the complex societies and apparent intelligence of dolphins and whales be considered both 'remarkable' and 'unexplained'?) and there is no sense that social relations may, in fact, represent a highly productive way to solve one's ecological problems (as made abundantly clear by Dunbar \& Shultz, 2007a,b; see also Reader \& Laland, 2002; for cetaceans, Rendell \& Whitehead, 2001). For example, the delphinids, which are all highly social, require skills relating to the ability to hunt, secure prey, and avoid predation and other dangers. Mothers take care of their young for protracted periods of time, and in several matriarchal societies, female offspring remain with their mothers (and aunts and half-aunts, etc.) for many years (reviewed by Gowans, Würsig, \& Karczmarski, 2008; Wells, Boness, \& Rathbun, 1999). This is so especially for those that eat squid far below the surface (including the non-delphinid sperm whale, Physeter macrocephalus), and we surmise that feeding on this energy-poor food at depth needs special skills that are learned by young over the years. Those that corral prey show high degrees of coordination, apparent cooperation, and engage in bonding rituals that seem necessary for securing prey (Vaughn, Würsig, Shelton, Timm \& Watson 2008; Würsig \& Würsig, 1980).

Similar sophistication is indicated in avoiding sharks and killer whales (Weller, 2009 provides an overview), and in mating rituals, but we know less here (Gowans et al., 2008). In other words, and as Sterelny (2007) has suggested, there are likely to be synergies between ecological and social factors that explain why certain species show greater behavioral flexibility than others, and have undergone evolutionary increases in brain size. Humphrey's argument only makes sense in the context of his explicitly anthropocentric project, which is to explain increased brain size in the primates, and humans in particular; this becomes clearest in the final third of his paper, when he deals with the way in which the 'misplaced' application of our social intelligence may underlie some of humans' other intellectual achievements in other domains.

We should make clear that we are not saying there is something wrong with Humphrey's writings on this issue - it is quite obviously presented as a hypothesis to be tested, not as a statement of fact - but Humphrey's ideas have colored the way in which the theory subsequently developed. This was no doubt aided and abetted by the publication by Premack and Woodruff's (1978) classic "Does the chimpanzee have theory of mind?": a paper that similarly took an explicitly anthropocentric perspective to the question of primate psychology. Together, these papers helped set the stage for the emergence of the "Machiavellian Intelligence Hypothesis" (Byrne \& Whiten, 1988). The use of the word "Machiavellian" was not intended to imply that social life was all about deceit, manipulation and self-serving plotting and planning to out-wit the competition (although Humphrey certainly emphasized these skills), but rather that success in social life was achieved by having an insight into what made other animals tick and exploiting that knowledge accordingly. Being able to function well in society meant understanding the psychological processes that underpinned behavior, rather than simply taking things at face value. Social life, in other words, was really about what went on in the head, and the attempt to manipulate the contents of another animal's head to one's own advantage.

Although subsequent work revealed that monkeys, at least, were not capable of the kinds of "mindreading" skills proposed initially (Cheney \& Seyfarth, 1990) (and the data on great apes is very much open to debate, see Vonk \& Povinelli, 2006; Tomasello, Call, \& Hare, 2003), the idea that social life is complex because animals needs to track certain abstract conceptual qualities-specifically, the nature of social bonds between animals, whether their own or those of others-has persisted (e.g., Bergman, Beehner, Cheney, \& Seyfarth, 2003; Cheney \& Seyfarth, 2008; Seyfarth \& Cheney, 2013; Silk, 2007). This, in turn, has continued to fuel the assumption (still not fully tested) that large brains indicate the possession of greater intelligence, and more specifically, a particular kind of cognitive architecture designed to perform a complex social calculus based on some form of relationship tracking (Healy \& Rowe, 2007). Finally, we suggest that it has promoted a form of "yardstick science," where Humphrey's anthropocentric ideas of what social intelligence consists in have been extended and then applied to other species, such as the cetaceans, corvids and hyenas, whose level of social intelligence is assessed by how 
well they measure up to a particular set of primate-biased criteria.

\section{Why delphinids are neither 'naked' nor 'aquatic apes'}

This problem is particularly acute when we consider comparisons between primates and members of the cetacean order, particularly the delphinids. While the use of simple one-to-one comparisons between the social systems, brain size and social skills of different taxa is acceptable as a first pass at testing the social intelligence/social brain hypothesis, ultimately, it will not be satisfactory precisely because there is no principled reason to expect that aquatic mammals, whose lives are very different in so very many ways, should map onto a terrestrial, mammalian, largely primate-oriented pattern.

A recent, and ongoing, controversy in the cetacean literature helps to illustrate this point. Manger (2006) put forward the claim that the cetacean brain was not designed for complex cognition, but was instead a "thermogenic" organ, an adaptation to cold temperatures. In order to advance his hypothesis, Manger (2006) presented an extended critique of studies of cetacean brain size evolution and cognition, as well as claiming positive evidence for the relation between brain size and the temperature range in which species were found. While a number of Manger's claims and data do not stand up to close scrutiny (Marino et al., 2008), and his dismissal of cetacean intelligence was extreme (see also Manger, 2013), his hypothesis has the virtue of treating cetaceans as cetaceans - as a taxon distinctively different in many ways from the primates. Cetaceans are large aquatic mammals, many of which are pursuit predators. Their lives are different in many ways from those of primates, notwithstanding certain similarities with respect to sociality. Their brains are structured differently, reflecting the manner in which selection has acted on their sensory and motor systems. In particular, the odontocetes use sonar, and thus perceive the world differently from the visually oriented primates. Their ears are so well-adapted to life underwater that they can detect and locate even subtle sounds in a very noisy milieu. In addition, cetaceans do not have hands, and cannot manipulate the world like a primate, and certain means of exploiting and exploring their environments are thus precluded. Is it reasonable to suppose that these facts make so little difference to how these animals deal with the ecological and social challenges they face?

If we leave aside Manger's specific criticisms of work in cetacean cognition, recently revisited in a second paper (Manger, 2013), the most notable aspect - and this is something that is also apparent in Marino et al.'s (2008) response to Manger (2006) - is how anthropocentric (or at least "primatocentric") most of the work on cetacean cognition has been. It is this, perhaps, that lies at the heart of Manger's (2006, 2013) criticism: by focusing on the convergent nature of cetacean and ape cognition, cetacean quiddity (i.e., its inherent nature) is almost completely neglected. One could argue, then, that Manger's positive contribution is to correct this imbalance (see also Rauch, 2001 for a similar point about the 'reluctance' to deal with cetaceans in these 'pragmatic' terms).

Consider vocal communication. As Manger (2006) rightly points out, the constraints of living in an aquatic habitat limit the possibilities for communication in the visual modality: their streamlined bodies are homogenous, they have no limbs, and their facial musculature does not permit the formation of facial expressions. Olfaction is similarly limited due to the lack of an olfactory bulb in odontocetes and its atrophied nature in mysticetes. The vocal channel is the one that affords most possibility for communication and it is therefore no surprise that it is the most highly developed. Whether its sophistication is indicative of high-level referential and symbolic understanding is more open to debate. Manger's (2006) view is that it indicates nothing of the sort, a stance challenged fiercely by Marino et al. (2008). The point we want to emphasize here, however, is that claims for the sophistication of cetacean vocal communication have been made by explicit reference to its similarity to human language (even though it is recognized that it does not itself constitute true language, e.g., Richards, Wolz, \& Herman, (1984) or the nature of the supporting cognitive structures, which are similarly anthropocentric and centre on symbolic understanding (e.g., Herman, Pack, \& Woods, 1994; Herman, Richards, \& Wolz, 1984). Similar claims have been made for primate vocalizations, of course, and this is not a criticism of such studies per se. Rather, our point is to highlight how the case for dolphin social intelligence has frequently hinged on its similarity to ape social intelligence, which itself is hinged on a human standard of social 
intelligence, with tests for mirror self-recognition (Reiss \& Marino, 2001), language and symbolic comprehension (e.g., Herman et al. 1984, 1990, 1994, 2001), understanding of human pointing and head gaze (e.g., Pack \& Herman, 2007), imitation and the cultural transmission of behavior (e.g., Deecke, Ford, \& Spong, 2000), teaching (Guinet \& Bouvier, 1995) and tool use (Krützen et al., 2005).

Manger (2013) subjects all such studies to an extended critique, arguing that the evidence is either (a) inadequate to support such a claim for these skills as indicative of high-level cognitive skills, or (b) that such capacities are wide-spread in the animal kingdom, and hence cannot be used to account for any unique cetacean increase in cognitive capacity. No doubt these new claims will also be contested, but to continue the debate in this vein, we would argue, misses the point. In our view, this anthropocentric focus is really more of a wasted opportunity than a claim for skills that cetaceans do not possess.

What do we mean by this? Let us consider again the highly sophisticated echolocation of the delphinids and the sperm whales (Au, 1993, 2009). Largely from work with bottlenose dolphins, we know that they can detect and process even slight differences in size and densities of objects. Behavioral observations indicate that dolphins may acoustically "see" into each other's bodies, and the implications of such a different sensory modality have not been seriously explored (Au, 1993). In other words, the idea that smiles are frozen and that gestures are limited may mean very little, as echolocation "buzzes" directed at each other may allow the animals to pick up relevant information about others (e.g., identifying one that has recently fed from one whose stomach is currently empty) and to signify certain emotional states (Brownlee \& Norris, 1994) in ways that have no simple and direct analogue to visual signaling. In this regard, it is interesting that the only recent reference to such abilities we found was a story widely circulated on a variety of internet news sites that suggested that "Dolphins may detect pregnancy in women using echolocation" (Huffington Post, July 11 2013; http://www.huffingtonpost.com/2013/07/11/dolphins-may-detect-pregnancy_n_3581991.html). Once again it seems the abilities of these creatures, as remarkable as they are, are deemed interesting only to the extent that we can find a way to relate them to our specifically human concerns...

As with the primate work, a historical perspective helps to put the anthropocentric focus of cetacean research into perspective: that is, a comparison of skills, such as the understanding of referential gestures, is perfectly valid in the context of the social intelligence hypothesis as initially formulated and subsequently developed. Indeed, one could go further and argue that the investigation of these capacities in cetaceans actually represents an effort to undermine Humphrey's (1976) anthropocentric focus, via the demonstration that particular skills deemed crucial to the evolution of intellect in the primate order are found in other species. Even if this argument is made, however, our point remains valid because it is clear that any such research effort remains, at base, an endeavor in which human-like skills are taken as the yardstick.

Again, we can consider Manger's $(2006,2013)$ criticisms as a case in point. His argument with respect to the dolphin brain is based, at least in part, on differences between the structure of the cetacean cortex compared with that of primates. His assumption, then, is that primate-like cognition depends on a primate-like cortical structure. As the dolphin cortex is so different from that of the primates, the similarity in their cognition is, according to Manger (2006), an illusion based on the over-interpretation of an inadequate experimental research base. As Kirsh, Güntürkün, and Rose (2008) have shown for avian species, however, very different kinds of brains can converge on similar kinds of cognitive abilities. That is, bird brains are also structured very differently from those of primates, but many corvids possess certain skills, like episodic-like memory, that are also found in humans; thus, there is no logical force to this kind of 'primate cortex is special' argument. Having said this, one can also see that the 'cortex is special' supposition arises precisely because the social intelligence hypothesis has been anchored to a specific suite of skills thought to be highly characteristic of human and primate intelligence. In turn, these have been tied to particular brain regions with little rigorous testing of whether particular brain regions underpin the specific skills suggested (Healy \& Rowe, 2007). One could be forgiven for inferring that, as a result, primate-like intelligence must be tied to the specific structure of the primate brain (and for all we know, this may well be true in some important primate-specific ways, although we have no solid empirical grounds for accepting this as yet). 
It is also the case that, as already mentioned, many of the tests presented to dolphins lack ecological validity and show little sensitivity to the animals' evolved anatomy and the niche they occupy; again, one could be forgiven for inferring that the specific aim of such studies has been to show the convergence of primate-like intelligence in another taxa, as opposed to tackling the issue of how cetacean brains give rise to any distinctively cetacean forms of cognition (indeed, one doesn't always have to infer this: Marino (2002), for example, is explicit about the convergence between primate and cetacean intelligence butand again to highlight our main point - the skills emphasized include the very human-like traits of "artificial 'language' comprehension and self-recognition"). We can put this another way: even if we accept that cetaceans are capable of all the cognitive feats on which they have been tested, does this really give us an insight into what is distinctive about cetacean social intelligence? Can a research program that ignores the nature of a species' body and the ecological niche it occupies truly give an insight into the forms that natural social intelligence can take? We would suggest not.

We can also frame our point like this: Delphinid cetaceans (and probably at least several other species of the odontocete suborder, sperm whales, monodonts, and perhaps some beaked whales) are highly social creatures with large and well-developed brains. All odontocetes are carnivorous (in the general "meat-eating" sense as opposed to herbivory or omnivory), and none are batch-feeding strainers or sievers like most of the mysticetes (with gray whales, Eschrichtius robustus, being the only "grazers", on in-benthic worms and such). This means that none are grazers or browsers such as the ungulates, and all must "work for" - find, hunt, corral, secure, and ingest - their generally highly active prey. Many open ocean delphinids, however, occur in huge schools or groups (up to several thousand individuals) that seem to act like grazers, such as wildebeest (Connochaetes spp.) or caribou (Rangifer tarandus). They are constantly on the move, perhaps to outrun their more stationary predators, to avoid radically reducing their prey in a particular area, or both. Yet, within this basic school structure, there is evidence for longterm bonds between kin (for example, pilot whales, Globicephala spp., Amos, Schlötterer, \& Tautz, 1993; Kasuya \& Marsh, 1984) and non-kin (dusky dolphins, Lagenorhynchus obscurus, Markowitz, 2004). We imagine that long-term learning, the existence of social bonds, and individual knowledge of others within specific sub-groups exists within these large herds. We also know that at least in some cases, tight foraging coordination takes place. In this sense, dolphins can be large-herd "grazers," small group hunters (wild dogs come to mind), and tight long-term social parties (apes and perhaps some other primates) at one and the same time (Gowans et al., 2008). This means that there is no clear analogue or neat comparison to be made here with a particular terrestrial taxon and-as should be apparent from our own attempts to do so-trying to generate such comparisons leads to an inappropriate pigeon-holing of cetaceans into terrestrial terms that we grasp more intuitively. The challenge, then, is to resist such simplification and attempt to tackle delphinid sociality and its cognitive consequences on its own terms.

\section{Questioning the social intelligence hypothesis - one species at a time}

A similar dissatisfaction with the social intelligence hypothesis has been articulated by Holekamp (2007). This discussion was focused on its application to carnivores, noting that, inter alia, the social intelligence hypothesis fails to capture the precise mixture of constraints and abilities that characterize the behavior of spotted hyenas, nor can it explain, why, for example, bears are so much more behaviorally flexible than other carnivores despite their more solitary nature (see also Holekamp, Swanson, \& Van Meter, 2013 for further discussion of developmental constraints on behavioral flexibility within the hyenas).

As we have suggested above, the source of this dissatisfaction may lie in the failure of the social intelligence hypothesis to recognize that sociality is likely to interact in synergistic (and possibly antergistic: Holekamp et al., 2013) fashion with ecological factors specific to a given taxon. Holekamp et al. (2013) argue, for example, that bite-force, and hence jaw musculature, places inherent limits on brain size expansion among the hyaenids. Another reason is that, by assuming social intelligence is 'all in the head' and that complex behavior is underpinned by complex cognitive operations, the 'embodied, embedded' nature of natural cognition goes unrecognized (Barrett, 2009, 2011; Barrett \& Henzi, 2005; 
Barrett, Henzi, \& Rendall, 2007). Failing to recognize that the ways in which an animal perceives and acts in the world are part and parcel of its cognitive capacities leads to a kind of inappropriate 'functionalism' or 'multiple realizability' (Searle, 1990), where all that matters are the abstract conceptual states to which sociality gives rise, and not the actual means by which animals engage with each other, and encounter the world around them. As we note above, appreciating that sonar is likely to afford cetaceans a different array of social and ecological opportunities compared to the mobile, colorful faces and grasping hands of monkeys, or the enlarged clitoris and robust jaws of spotted hyenas, may allow us to refine and extend the social intelligence hypothesis in ways that truly move it beyond its anthropocentric origins.

\section{Getting our bearings}

Let us pause to recap briefly. Current conceptions of social intelligence rest on the assumption that large brains house complex cognitive architectures, which in turn is based on heavily anthropocentric assumptions that such architectures are designed to deal with the difficulty of tracking abstract relationships with others across time within complex social groups. As such, current conceptions of social intelligence fail to recognize that other selective factors are likely to have a differential impact (or no impact at all) on different taxa, and they ignore the potential offered by alternative positions that consider cognition to be "extensive," and which include both the body and environment as part of the cognitive system (e.g., Barrett, 2011, Chemero, 2009, Hutto \& Myin, 2013). A positive solution to these problems is needed, and Holekamp (2007) lays out what she feels is needed to get things back on track.

One key issue she identifies is the need to make the social intelligence hypothesis more specific: how exactly do differences in social structure and inter-individual relations translate into differences in cognitive demands on, and the competencies of, the animals in question? This, in turn, requires that we get a better handle on what constitutes social complexity and how to measure it consistently and objectively. This is not a trivial issue because, as we have seen, part of the reasoning behind what makes a group complex is what the animal itself brings to the table as a 'calculating being.' Finding oneself among other similarly calculating beings sets in motion a ratchet that gradually increases the overall level of intelligence in the population because animals become trapped in a never-ending spiral of cognitive strategy and counter-strategy.

This raises problems of potential circularity, however, as Gigerenzer (1997) has pointed out: primate groups are argued to be complex because the animals that live in them are complex, but primates are argued to be complex animals because they live in complex groups. As should be apparent, this argument is not only circular, but it also begs the question with respect to social complexity. Indeed, in the primate literature, there is neither clear definition nor measure of social complexity, and again, circularity persists in the attempts to identify it. Lehman and Dunbar (2009), for example, correlate brain size and neocortex ratio with various social network metrics on the assumption that significant correlations enable the identification of complex network structures, despite the fact that the measures of complexity identified in this way are not then independent of brain size and so, strictly speaking, cannot be used to test the social brain hypothesis. These somewhat nebulous, primate-centric notions of social complexity are then applied to other taxa in ways that become self-reinforcing: whatever form of social structure is identified as a correlate of large brain size must, by definition, be cognitively demanding because the animals' enlarged brains demonstrate this is the case. In addition to more fully recognizing the embodied and situated nature of cognition, a taxon-neutral means of quantifying social complexity is required if we are to further the development of the social intelligence hypothesis in ways that allow it to be applied across species as diverse as the primates and cetaceans in a fair and unbiased manner. Although we fully admit we have no clear answer to this problem at present, we offer some suggestions that might be worth considering.

Our inspiration here comes from work not on primates or cetaceans, or even hyenas, but from rats (Pellis \& Pellis, 2009); in particular, recent work on the manner in which play-fighting influences brain development (Bell, 2008; Bell, Pellis, \& Kolb, 2010). Part of the importance of this work lies in its 
emphasis on how, first and foremost, it is behavior that shapes the brain, rather than vice versa. Neuronal development (e.g., the complexity of dendritic arbors) of the orbito-frontal cortex (OFC) was found to be influenced by the number of social partners experienced during development, but was not influenced by the experience of play as such. In contrast, young rats raised with peers (who engage in frequent play) show differences in the development of the medial pre-frontal cortex compared to young rats raised only with adults (who do not engage in play to the same extent, if at all), i.e., the PFC is influenced by the experience of play specifically, and not just social interaction per se (Bell, 2008; Bell et al., 2010). This work suggests that OFC development is sensitive to the number of partners present, while the PFC development is sensitive to the identity of those partners in terms of the different types of physical interactions undertaken with them. Together, these areas are linked to the production of appropriate behaviors in specific social contexts.

These findings are intriguing because they suggest a way in which social complexity potentially can be deconstructed. First, there is the quantitative component of the number of different partners encountered. To put it crudely, OFC development is linked to the ways in which the presence of a number of different individuals affords certain kinds of social interactions that are unavailable to animals raised with greater or smaller number of social partners. Second, each category of partner (in the rat case, peers versus adults) affords qualitatively different kinds of actions and experiences. Again, crudely speaking, the PFC development is linked to the ability to generate appropriate behaviors with particular categories of partner. Hence, the greater number of different categories of potential partner present, and the greater number of individuals within each category, the greater the demands placed on an animal in terms of producing appropriate behavior, and by extension, the more behavioral flexibility one should expect to see in a group of a particular structure and size (see also Freeberg, Dunbar \& Ord 2012). This does not necessarily entail 'complexity' in the formal mathematical sense in which the term is often used, but it does present animals with a complicated social environment, and we can measure and assess this kind of complexity in a number of ways.

This may not, at first blush, seem all that different from the qualitative-quantitative characterization suggested by Dunbar (1998; Dunbar \& Shultz, 2007); but unlike Dunbar (1998) and Humphrey (1976) before him, our proposal does not posit the need to monitor abstract relations nor does it suggest that we have to develop a particular conceptualization of what it means to have a 'bond' with another individual. Instead, it deals with the concrete, observable affordances (i.e., the possibilities for action) that animals offer each other (Barrett, 2011; Barrett \& Rendall, 2010; Gibson, 1979). As such, it places the emphasis on contingent responses to immediate social opportunities (as opposed to prospective assessment in the abstract). As an added bonus, this view regards developmental processes, and more specifically, epigenesis, as the key to producing an animal capable of flexible, contingent behavior.

To be fair, Humphrey (1976) also suggests that groups composed of different generations will be more complex, but, of course, he frames this in terms of the inherent conflict of interests that this generates, and the consequent need to exploit and out-maneuver others. The suggestion here differs by positing simply that a variety of partners, which afford a variety of different interactions, will produce a situation sufficiently complex in itself to require a certain degree of behavioral plasticity. If we add to the mix how the value of different partners varies as a function of their reproductive status, changes in rank, health, and ecological factors such as season of the year, then the degree of complexity in the 'biological marketplace' can be assessed quantitatively not only across species, but also within species, and populations within species, over time (Barrett \& Henzi, 2006; Noë, 2006).

There is an additional component we can add here that may give us further purchase on what it means for a grouping to be considered complex. This is the notion of 'frustration.' Consider a group of three individuals involved in a kind of 'love triangle': A and B both engage with C, but do not engage with each other. This kind of network is "frustrated;" the links are not reciprocal (A. Cavagna, personal communication, August 2007.). The degree to which a social network can be considered complex therefore rests on the degree to which frustration of this kind exists. The notion of frustration thus captures the way in which preferences and affordances may vary across individuals across time, and hence brings in the dynamic nature of social interaction that Humphrey (1976), Jolly (1966), and Chance 
and Mead (1953) identified as key to differentiating group-living from more solitary forms of existence and from mere gregariousness.

\section{Patterns and attractor states}

An emphasis on the need for animals to respond contingently to the opportunities and possibilities for action offered by other individuals whose availability varies in both space and time is, as argued elsewhere (Barrett, 2011; Barrett et al., 2007; Barrett \& Rendall, 2010), a viewpoint that suggests that social understanding can be considered as a form of non-analytic pattern-recognition, that is best modeled and understood as embodied in the patterns of activation of neuronal units linked in distributed networks (Clark, 1993), rather than as some form of logical, syntactically-organized computation. The social world is clearly structured in ways that powerful associative learning principles can exploit. Specifically, the juxtaposition of particular individuals with particular behaviors with particular contexts can form the basis for an association matrix from which individuals can distill higher-order associations that enable them to respond appropriately to novel situations. Landauer and Dumais (1997), for example, have shown precisely how this kind of process (singular value decomposition followed by dimension reduction) can produce neural networks that comprehend written text, starting from only an association matrix of experienced words and the contexts in which they occurred. (This "latent semantic analysis" approach has also been applied to the song lyrics of The Beatles, tracing how John Lennon's, Paul McCartney's, and George Harrison's lyrical style and subject matter changed over the course of their career together, as well as identifying who exerted the most influence on whom: Petrie, Pennebaker, \& Sivertsen, 2008). If such non-symbolic non-analytic processes can produce text comprehension, i.e., the archetypal example of cognition-as-computation, involving symbol manipulation according to a set of rules, it does not seem so outrageous to suggest that the 'calculus' of social life can be dealt with in this non-analytical fashion. Indeed, Lusseau (2003) sheds light on the power of social network analysis to explore these issues; established networks can adjust and restructure following the removal of particular individuals in ways that ensure network integrity persists through time. Further work by Lusseau, using baboon data, has similarly shown that perturbations in network structure lead individuals to adjust their behavior in ways that restores the "certainty" of the network, i.e., the degree to which behavioral interactions are predictable and regulated (Barrett, Henzi \& Lusseau, 2012). This suggests that statistical structure picked up via social network analysis may also be 'visible' to the animals themselves in ways that allow them to respond and adjust to any disruption of the network. Lusseau (2007) further suggests that, in the case of delphinids, it is the formation of mixed-sex schools with sophisticated social structure that allows for the "democratic" sharing of information and the formation of group decisions, again implying that animals may be sensitive to certain kinds of statistical information that structure their everyday social interactions.

Rendall (2004) has also suggested that this kind of mechanistic explanation can explain why kin recognition in primates appears to be based purely on familiarity, rather than more specialized mechanisms such as phenotype matching. Since neural networks require experience for their operation, they have the flexibility needed to cope with changes in cue features over time (as naturally happens as individuals develop and age) that other more deterministic mechanisms lack. The experiential plasticity of neural networks also allows a continuous updating of social signals, which can therefore account for why animals are so proficient at the perceptual tracking of changing social cues (Rendall, 2004). This kind of flexible, experientially-informed pattern-recognition may, we suggest, go beyond kin recognition, and form the basis for much of social cognition in non-linguistic animals (Barrett, 2009; Barrett et al., 2007; Barrett \& Rendall, 2010); it may also help us to explain patterns of innovation and social learning, as documented by Reader and Laland $(2002,2003)$.

Interestingly, from our perspective, with its emphasis on cognition as flexible action in the world, rather than on cognitive processes of a more propositional variety, computational neuroscience has shown that formal neural networks often give rise to emergent properties that were not explicitly programmed by their designers (Carpenter \& Grossberg, 1988; Grossberg, 1987, 1988; Hopfield, 1982). Most relevant here are attractor states. Put very crudely, these are networks of interconnected neurons that can show a 
stable pattern of activity in the absence of any direct outside stimulation (Cossart, Aranov, \& Yuste, 2003; Fuster, 2003; Hopfield, 1982). Such states are possible because the connections between neurons are of sufficient strength that the activation of any sub-set is sufficient to keep the pattern as a whole going (Grossberg, 1987, 1988). Attractor states also show "basins of attraction," wherein sets of similar, but not identical, activity patterns are recognized by the system as being equivalent, and can therefore transform the network into an attractor state (Grossberg, 1987, 1988). Similarly, Kohonen (1984) argued that selforganization in the cortex according to Hebbian principles of repeated stimulation for energizing synaptic plasticity can produce associative memory networks, such that perception and recognition becomes a process of pattern completion, where part of a memory could activate the entire network and all of its associated components. Making sense of an external event therefore occurs when sensory input can trigger the formation of relevant attractor states (adaptive resonance theory (ART): Carpenter \& Grossberg, 2010). Since attractors can be distributed over widely distributed cortical areas, input from different sensory modalities could be combined in a single attractor state, and the fact that they are emergent means that they could be tuned to an animal's specific encounters with other individuals (and other objects in the world). Thus, over time, individuals would accumulate a variety of latent patternrecognizing attractor states, which would enable quick decisions to be made, and solutions to be found, to a wide range of problems.

This is crucial from a social cognition perspective because deciding what to do next is the main problem facing individuals in the social world, and such decisions must be made quickly, because other individuals are also making decisions and acting in contingent ways, as all social intelligence theorists have noted (Barrett et al., 2007; Byrne \& Whiten, 1988; Chance \& Mead, 1953; Dunbar, 1998; Humphrey, 1976; Jolly, 1966). Knowing what to do next, then, is also a process of pattern recognition and completion, and may explain why animals often act appropriately, despite never having been taught a particular contingency or encountered a specific situation-behaviors that Rumbaugh and Washburn (2003) refer to, appropriately enough, as "emergents."

At present, we do not know how the kinds of attractor states identified in computational neuroscience map onto real brains. In addition, this suggestion is no doubt vulnerable to some of the criticisms put forward by Healy and Rowe (2007) (although it does answer their question as to why more neural tissue per se should be considered an advantage). Nevertheless, the emergence of attractor states over time fits neatly with findings from the primate literature; in particular, those showing that social learning and socialisation appear to be crucial in development for normal adult functioning (e.g., Pellis \& Pellis, 2009; Suomi \& Harlow, 1975), and why different social mileus and developmental backgrounds can influence the degree to which individuals are socially skilled as adults (e.g., Strum, 1982, 1994).

This kind of pattern-recognition model can also explain why more behavioral variety and flexibility in response is found in those species with large forebrains, such as in primates, delphinids, corvids and elephants, because this presumably allows for the emergence and accumulation of more or larger or more widely distributed pattern-recognizing networks and attractor states. It also helps explain the patterns of correlated evolution in the cerebellum and neocortex, given that the skills needed are those required to produce adaptive, dynamic action in an unpredictable world, rather than to simply produce abstract constructs of that world (Barton, 2012). This may also explain why, in their careful analysis of primate brain size variation, Deaner, Barton, and van Schaik (2003) found that brain size was significantly related only to lifespan and not to any other ecological, social or life-history variable. While such relationships have been characterized merely as the lifting of constraints on brain size evolution (one needs to live longer to spend time growing a large brain: Dunbar \& Shultz, 2007b), one can also see how a longer lifespan could itself drive selection for larger brain size if more and larger attractor states are needed to cope with the higher levels of variability in terms of both ecological factors and social factors that are likely to be experienced: an argument that bears comparison with the 'cognitive buffering' hypothesis (Sol, 2009; see also Ricklefs \& Wikelski, 2002). After all, as argued elsewhere (Barrett et al., 2007; Rendall, Notman, \& Vokey, 2008), the data to be explained are the large amounts of neural tissue that characterize creatures such as the primates and cetaceans, and large, highly interconnected pattern-recognizing attractor states require a lot of neural tissue to implement. Long-lived animals may need more neural tissue because they 
need a larger number and variety of attractor states that enable them to respond flexibly to novel conjunctions of events.

This suggestion also resonates with the findings relating to 'culture' among cetaceans and ape species (Rendell \& Whitehead, 2001; Whiten et al., 1999). While the attribution of culture to cetaceans in particular remains controversial (as the commentaries on Rendell and Whitehead's (2001) paper reveal, largely due to different definitions of what counts as "cultural"), from the point of view of the present discussion, this is irrelevant. What matters is how these findings speak to the flexibility of behavior shown both between and within populations of cetacean species, and their ability to respond to novel affordances in an interesting and flexible fashion. This point becomes even more pertinent if we consider the role that niche construction (Odling-Smee, Laland, \& Feldman, 2003) may play in both primate and cetacean society, where the animals' own actions in the environment can change the nature of the selection pressures that impinge upon them. If some of the variability in an animal's socioecological environment is produced by its own actions, or it inherits an ecology transformed by others, one can see how large brains that permit niche-constructing actions would then "select for themselves", in the kind of ratchet mechanism envisaged by Humphrey (1976).

Within the broader context of niche construction, Sterelny (2004) has also written of how animals may 'epistemically engineer' their environments, so transforming the informational context in which they operate. Long-range contact calls or songs, for example, allow animals to monitor the position of other individuals in space by making it easy to localize their position, and these kinds of vocal dialects and traditions are extremely well developed in some cetaceans (e.g., Deecke et al. 2000; Ford, 1991; Yurk, Barrett-Lennard, Ford, \& Matkin, 2002). Similarly, the suggestion that, by dispersing seeds along particular travel paths, spider and woolly monkeys could help transform the structure of tropical forests, so constructing their own ecological niche, and also epistemically engineering their environment by making it easier to locate and remember route foraging routes fits beautifully with these ideas (Di Fiore \& Suarez, 2007).

Attending to the precise ways that animals act in the world and what their actions afford to themselves and others helps to create a better understanding of how they create and structure their worlds in 'intelligent' ways; ways that don't necessarily require wholly internal brain-based cognitive strategies, but where the structure of their bodies and the environment can bear some of that cognitive load (Barrett, 2011; Barrett et al,. 2007; Clark, 1997, 2008). This, perhaps, is also what Rendell and Whitehead (2001) were getting at when they argued that more attention should be paid to cetacean 'cognition in the wild' as opposed to a focus on laboratory experimentation. By definition, laboratory experiments need to control the environment in ways that can isolate the phenomenon of interest. If, however, the phenomenon of interest is one that is scaffolded and supported by a particular environmental context, then we may fail to identify its true nature and perpetuate the idea that cognition is always and entirely in the head; a view that is increasingly undermined by work in evolutionary robotics and artificial life (Brooks, 1999; Pfeifer \& Bongard, 2007; Pfeifer \& Scheier, 1999). We are not, of course, the first people to suggest this, and there exists a small but vibrant literature that tackles issues of behavioral flexibility from this more relational, embodied, and less cognitivist point of view (e.g., Forster, 2002; Herzing, 2006; Johnson, 2010; King, 2004; King, 2005; Russon, 2006;).

\section{Embodied, affective action in the world}

We conclude by offering one example of how a more embodied approach can be employed, by describing the manner in which different species use similar kinds of behavioral coordination during coalition formation (where two or more animals jointly direct aggression against a third). In both monkeys and dolphins, this behavior is characterized by close bodily synchrony and coordination between partners. Among baboons, for example, female coalitions (which are very rare occurrences) involve the participants standing shoulder-to-shoulder and advancing on the target of their aggression in tight formation (Henzi \& Barrett, 2007). Capuchin monkeys also show this kind of close bodily contact, but they orient themselves vertically, one on top of the other (known as an 'overlord') so as to present a 
column of threatening faces toward their target (e.g., Perry, Barrett, \& Manson, 2004). In similar fashion, dolphin males surface and swim together in an equally coordinated fashion during aggressive coalitions (Connor, Smolker, \& Bejder, 2007). Such tight behavioral coordination may serve to signal solidarity among the coalition partners, and is no doubt a more intense and threatening stimulus to the target. It is, as Owren and Rendall $(1997,2001)$ argue, a form of 'affect induction,' where actions are designed to influence directly a target's nervous/physiological systems, rather than as a means of 'communicating' information about the likelihood of attack, or the nature of the relationship that exists between coalition partners. As importantly, such behavioral coordination can be seen as a form of affect induction for the participants: close bodily contact during an aggressive encounter may well serve to keep coalition partners' stress at lower levels, despite high arousal and the stressful nature of the situation. In doing so, it may reduce the costs of such aggression for participants, especially relative to those of the target, who lacks any such form of "contact comfort."

Affect induction is, by definition, an embodied perspective on how animals regulate their own behavior and that of others: it focuses on physical actions and engagement with the world, and considers physiological responses produced in the body as part and parcel of an animal's cognitive response. As such, it provides us with a way out of the anthropocentric bind in which comparative studies of social intelligence are situated currently.

An understanding of manner in which the perception of others, and an animal's own actions, afford a particular kind of interaction and induce a particular kind of affect, and how this influences the subsequent sequencing and patterning of behavior (in both the short- and long-term) provides us with the means for comparing species in a fair manner. Identifying and investigating how cognitive processes have their basis in bodily-situated engagement with the physical and social worlds that they inhabit may hold the key to understanding the kinds of complex worlds that primates and cetaceans potentially create for themselves.

\section{Conclusion}

Our take-home message is that reconfiguring the social intelligence hypothesis by placing greater emphasis on what animals actually do when they act socially, and the variability and flexibility of their behavior, rather than inferences regarding the nature of their complex internal representations, will lead automatically to a more embodied, more ecological approach that allows a given species to 'speak with its own voice.' It is an approach that can identify true commonalities among taxa in their natural behavior, rather than the artificial commonalities produced by laboratory or field tests for qualities like mirror selfrecognition or symbolic comprehension. This isn't to denigrate the work that has been done in these areas, especially as it helps confound any suggestion that humans are unique with respect to certain kinds of complex and interesting behaviors. Its anthropocentric origins do need to be acknowledged, however: a species shouldn't be judged solely on its ability to pass tests that, in the main, stem from our desire to know whether other species share similar cognitive skills to our own.

\section{Acknowledgements}

Thanks to David Lusseau, Michael Krützen, Ronald Noë, and Peter Henzi for interesting discussions and input on these issues.

\section{References}

Amos, B., Schlötterer, C., \& Tautz, D. (1993). Social structure of pilot whales revealed by analytical DNA profiling. Science, 260, 670-672.

Au, W. W. L. (1993). The sonar of dolphins. New York: Springer Verlag.

Au, W. W. L. (2009). Echolocation. In W. F. Perrin, B. Würsig, \& J. G. M. Thewissen (Eds.), Encyclopedia of marine mammals, $2^{\text {nd }}$ ed. (pp. 348-357). Amsterdam: Academic/Elsevier Press. 
Ballerini, M., Cabibbo, N., Candelier, R., Cavagna, A., Cisbani, E., ...Zdravkovic, V. (2008). Empirical investigation of starling flocks: A benchmark study in animal behaviour. Animal Behaviour 76, 201-215.

Barrett, L. (2009). A guide to practical babooning: Historical, ecological and cognitive contingency. Evolutionary Anthropology, 18, 91-102.

Barrett L. (2010). Too much monkey business. In G. Semin \& G. Echterhoff (Eds.), Grounding sociality: Neurons, minds and culture (pp. 207-224). Hove, UK: Psychology Press.

Barrett, L. (2011). Beyond the brain: How body and environment shape animal and human minds. Princeton, NJ: Princeton University Press.

Barrett, L., \& Henzi, S. P. (2005). The social nature of primate cognition. Proceedings of the Royal Society B: Biological Sciences, 272, 1865-1875.

Barrett, L., \& Henzi, S. P. (2006). Monkeys, markets and minds. In P. Kappeler \& C. P. van Schaik (Eds.), Cooperation in primates and humans: Mechanisms and evolution (pp. 209-232). Berlin, Germany: Springer-Verlag.

Barrett, L., Henzi, S. P., \& Lusseau, D. (2012). Taking sociality seriously: The structure of multi-dimensional networks as a source of information for individuals. Philosophical Transactions of the Royal Society B: Biological Sciences, 367, 2108-2118.

Barrett, L., Henzi, S. P., \& Rendall, D. (2007). Social brains, simple minds: Does social complexity really require cognitive complexity? Philosophical Transactions of the Royal Society B: Biological Science, 362, 561-575.

Barrett, L., \& Rendall, D. (2010). Out of our minds: The neuroethology of primate strategic behavior. In A. Ghazanfar \& M. Platt (Eds.), Primate neuroethology (pp. 570-587). Oxford, UK: Oxford University Press.

Barton, R. A. (1996). Neocortex size and behavioural ecology of primates. Proceedings of the Royal Society B: Biological Sciences, 1263, 173-177.

Barton, R. A. (1998). Visual specialization and brain evolution in primates. Proceedings of the Royal Society B: Biological Sciences , 265, 1933-1937.

Barton, R. A. (2013). Embodied cognitive evolution and the cerebellum. Philosophical Transactions of the Royal Society B: Biological Sciences, 367, 2097-2107.

Bell, H. (2008). Playful feedback and the developing brain (unpublished MS thesis). University of Lethbridge, Lethbridge, UK.

Bell, H., Pellis, S., \& Kolb, B. (2010). Juvenile play experience and the development of the orbitofrontal and medial pre-frontal cortices. Behaviour and Brain Research, 201, 7-13.

Bergman, T. J., Beehner, J. C., Cheney, D. L., \& Seyfarth, R. M. (2003). Hierarchical classification by rank and kinship in baboons. Science, 302, 1234-1236.

Brooks, R. (1999). Cambrian intelligence: The early history of the new A. I. Cambridge, MA: MIT Press.

Brothers, L. (1990). The neural basis of primate social communication. Motivation and Emotion, 14, 81-91.

Brothers, L., \& Ring, B. (1993). Mesial temporal neurons in the macaque monkey with responses selective for aspects of social stimuli. Behavioural Brain Research, 57, 53-61.

Brownlee, S. M., \& Norris, K. S. (1994). The acoustic domain. In K. S. Norris, B. Würsig, R. S. Wells, \& M. Würsig (Eds.), The Hawaiian spinner dolphin (pp. 161-185). Berkeley, CA: University of California Press.

Burkart, J. M., \& van Schaik, C. P. (2010). Cognitive consequences of cooperative breeding. Animal Cognition, 13, $1-19$.

Byrne, R. W., \& Whiten, A. (1988). Machiavellian intelligence: Social expertise and the evolution of intellect in monkeys, apes and humans. Oxford, UK: Clarendon Press,

Carpenter, G. A., \& Grossberg, S. (1988). The ART of adaptive pattern recognition by self-organizing neural networks. Computer, 21, 77-88.

Carpenter, G., \& Grossberg, S. (2010). Adaptive resonance theory. In C. Sammut \& G. Webb (Eds.), Encyclopedia of machine learning (pp. 22-35). New York: Springer. doi:10.1007/978-0-387-30164-8_11

Chance, M. R. A., \& Mead, A. P. (1953). Social behaviour and primate evolution. Symposia of the Society for Experimental Biology VII: 395-439.

Chemero, A. (2009). Radical embodied cognitive science. Cambridge, MA: MIT Press.

Cheney, D. L., \& Seyfarth, R. M. (1990). How monkeys see the world. Chicago: University of Chicago Press.

Cheney, D. L., \& Seyfarth, R. M. (2008). Baboon metaphysics. Chicago: University of Chicago Press.

Clark, A. (1993). Associative engines: Connectionism, concepts and representational change. Cambridge, MA: MIT Press.

Clark, A. (1997). Being there: Putting brain, body and world back together again. Cambridge, MA: MIT Press.

Clark, A. (2008). Supersizing the mind: Embodiment, action, and cognitive extension. Oxford, UK: Oxford University Press.

Connor, R. C., Smolker, R., \& Bejder, L. (2007). Synchrony, social behaviour and alliance affiliation in Indian 
ocean bottlenose dolphins, Tursiops aduncus. Animal Behaviour, 72, 1371-1378.

Cossart, R., Aronov, D., \& Yuste, R. (2003). Attractor dynamics of networks UP states in the neocortex. Nature, 423, 283-288.

Deaner, R. O., Barton, R. A., \& van Schaik, C. P. (2003). Primate brains and life histories: Renewing the connection. In P. M. Kappeler \& M. E. Perreira (Eds.), Primate life histories and socioecology (pp. 233265). Cambridge, UK: Cambridge University Press.

Deecke, V. B., Ford, J. R. B., \& Spong, P. (2000). Dialect change in resident killer whales: Implications for vocal learning and cultural transmission. Animal Behaviour, , 40, 629-638.

Di Fiore, A., \& Suarez, S. A. (2007). Route-based travel and shared routes in sympatric spider and woolly monkeys: Cognitive and evolutionary implications. Animal Cognition, 10, 317-329.

Dunbar, R. I. M. (1992). Neocortex size as a constraint on group size in primates. Journal of Human Evolution, 20 , 469-493.

Dunbar, R. I. M. (1993). Coevolution of neocortex size, group size and language in humans. Behavioral and Brain Sciences, 16, 681-735.

Dunbar, R. I. M. (1995). Neocortex size and group size in primates: A test of the hypothesis. Journal of Human Evolution, 28, 287-296.

Dunbar, R. I. M. (1998). The social brain hypothesis. Evolutionary Anthropology, 6, 178-190.

Dunbar, R. I. M., \& Bever, J. (1998). Neocortex size predicts group size in carnivores and some insectivores. Ethology, 104, 695-708.

Dunbar, R. I. M., \& Shultz, S. (2007a). Understanding primate brain evolution. Philosophical Transactions of the Royal Society B: Biological Sciences, 362, 649-658.

Dunbar, R. I. M., \& Shultz, S. (2007b). Evolution in the social brain. Science, 317, 1344-1347.

Dunbar, R. I. M., \& Shultz, S. (2010). Bondedness and sociality. Behaviour, 147, 775-803.

Ford, J. K. B. (1991). Vocal traditions among resident killer whales (Orcinus orca) in coastal waters of British Columbia. Canadian Journal of Zoology, 69, 1454-1483.

Forster, D. (2002). Consort turnovers as distributed cognition in Olive baboons: A distributed approach to mind. In M. Bekoff, C. Allen, \& G. M. Burghardt (Eds.) The cognitive animal: Empirical and theoretical perspectives on animal cognition (pp. 163-171). Cambridge, MA: The MIT Press.

Freeberg, T. M., Dunbar, R. I. M., \& Ord, T. J. (2012). Social complexity as a proximate and ultimate factor in communicative complexity. Philosophical Transactions of the Royal Society B: Biological Sciences, 367, 1785-1801. doi:10.1093/sysbio/45.3.290

Fuster, J. (2005). Cortex and mind: Unifying cognition. Oxford, UK: Oxford University Press.

Gärdenfors, P. (1995). Cued and detached representations in animal cognition. Behavioural Processes, 35, 263-273.

Gibson, J. J. (1979). The ecological approach to visual perception. Hillsdale, NJ: Lawrence Erlbaum Associates.

Gigerenzer, G. (1997). The modularity of social intelligence. In A. Whiten \& R. W. Byrne (Eds.), Machiavellian intelligence II: Extensions and evaluations (pp. 264-288). Cambridge, UK: Cambridge University Press.

Gowans, S., Würsig, B., \& Karczmarski, L. (2008). The social structure and strategies of delphinids: Predictions based on an ecological framework. Advances in Marine Biology, 53, 195-294.

Grossberg, S. (1987). Competitive learning: From interactive activation to adaptive resonance. Cognitive Science, $11,23-63$.

Grossberg, S. (1988). Neural networks and natural intelligence., Cambridge, MA: MIT Press.

Guinet, C., \& Bouvier, J. (1995). Development of intentional stranding hunting techniques in killer whales (Orcinus orca) calves at Crozet archipelago. Canadian Journal of Zoology, 73, 27-33.

Healy, S., \& Rowe, C. (2007). A critique of comparative studies of brain size. Proceedings of the Royal Society B: Biological Sciences, 274, 453-464.

Healy, S. D., \& Rowe, C. (2013). Costs and benefits of evolving a larger brain: Doubts over the evidence that large brains lead to better cognition. Animal Behaviour, 86, e1-e3.

Herman, L. M., Matus, D. S., Herman, E. Y., Ivancic, M., \& Pack, A. A. (2001). The bottlenose dolphin's (Tursiops truncatus) understanding of gestures as symbolic representations of its body parts. Animal Learning and Behaviour, 29, 250-264.

Herman, L. M., Morrel-Samuels, P., \& Pack, A. A. (1990). Bottlenose dolphins and human recognition of veridical and degraded video displays of an artifical gestural language. Journal of Experimental Psychology: General, 119, 215-230.

Herman, L. M., Pack, A. A., \& Wood, A. M. (1994). Bottlenose dolphins can generalize rules and develop abstract concepts. Marine Mammal Science, 10, 70-80.

Herman, L. M., Richards, D. G., \& Wolz, J. P. (1984). Comprehension of sentences by bottlenose dolphins. 
Cognition, 16, 129-219.

Herzing, D. L. (2006). The currency of cognition: Assessing tools, techniques and media for complex behavioral analysis. Aquatic Mammals, 32, 544-543.

Holekamp, K. (2007). Questioning the social intelligence hypothesis. Trends in Cognitive Science, 11, 65-69.

Holekamp, K. E., Swanson, E. M., \& Van Meter, P. E. (2013). Developmental constraints on behavioural flexibility. Philosophical Transactions of the Royal Society B: Biological Sciences, 368, 20120350.

Hopfield, J. J. (1982). Neural networks and physical systems with emergent collective computational abilities. Proceedings of the National Academy of Sciences, USA, 79, 2554-2558.

Hrdy, S. B. (2009). Mothers and others: The evolutionary origins of mutual understanding. Boston, MA: Belknap Press, Harvard.

Humphrey, N. K. (1976). The social function of intellect. In P. P. G. Bateson \& R. A. Hinde (Eds.), Growing points in ethology ( pp. 303-317). Cambridge, UK: Cambridge University Press.

Hutto, D. D., \& Myin, E. (2013). Radicalizing enactivism: Basic minds without content. Cambridge, MA: MIT Press.

Insel, T. R., \& Young, L. J. (2000). Neuropeptides and the evolution of social behaviour. Current Opinions in Neurobiology, 10, 784-789.

Jolly, A. (1966). Lemur social behaviour and primate social intelligence. Science, 153, 501-506.

Johnson, C. M. (2010). Observing cognitive complexity in primates and cetaceans. International Journal of Comparative Psychology, 23, 587-624.

Kasuya, T., \& Marsh, H. (1984). Life history and reproductive biology of the short-finned pilot whale, Globicephala macrorhynchus, off the Pacific coast of Japan. Report of the International Whaling Commission, Special Issue 6, Cambridge, U.K., pp. 259-310.

King, B. J. (2004). The dynamic dance: Nonvocal communication in African great apes. Cambridge, MA: Harvard University Press.

King, A. P., West, M. J., \& Goldstein, M. H. (2005). Nonvocal shaping of avian song development: Parallels to human speech development. Ethology, 111, 101- 117.

Kirsh, J. A., Güntürkün, O., \& Rose, J. (2008). Insight without cortex: Lessons from the avian brain. Consciousness and Cognition, 17, 475-483.

Kohonen, T. (1984). Self-organization and associative memory. Springer series in information sciences (Vol. 8). New York: Springer-Verlag.

Krützen, M., Mann, J., Heithaus, M. R., Connor, R. C., Bejder, L, \& Sherwin, W. B. (2005). Cultural transmission of tool use in bottlenose dolphins. Proceedings of the National Academy of Sciences, USA, 102, 89398943.

Kudo, H., \& Dunbar, R. I. M. (2001). Neocortex size and social network size in primates. Animal Behaviour, 62, $711-722$.

Landauer, T. K., \& Dumais, S. T. (1997). A solution to Plato's problem: The latent semantic analysis theory of acquisition, induction and representation of knowledge. Psychological Review, 104, 211-240.

Lefebvre, L., Reader, S. M., \& Sol, D. (2004). Brains, innovation and evolution in birds and primates. Brain Behaviour and Evolution, 63, 233-246.

Lehmann, J., \& Dunbar, R. I. M. (2009). Network cohesion, group size and neocortex size in female-bonded Old World primates. Proceedings of the Royal Society B: Biological Sciences, 276, 4417-4422.

Lusseau, D. (2003).The emergent properties of a dolphin social network. Proceedings of the Royal Society B: Biological Sciences, 270, 186-188.

Lusseau, D. (2007). Evidence for social role in a dolphin social network. Evolutionary Ecology, 21, 357-366.

MacLean, E. L., Barrickman, N. L., Johnson, E. M., \& Wall, C. E. (2009). Sociality, ecology and relative brain size in lemurs. Journal of Human Evolution, 56, 471-478.

Manger, P. R. (2006). An examination of cetacean brain structure with a novel hypothesis correlating thermogenesis to the evolution of a big brain. Biological Reviews, 81, 293-338.

Manger, P. (2013). Questioning the interpretations of behavioural observations of cetaceans: Is there really support for a special intellectual status for this mammalian order? Neuroscience, 250, 664-696.

Marino, L. (2002). Convergence of complex cognitive abilities in cetaceans and primates. Brain, Behaviour and Evolution, 59, 21-52.

Marino, L., Butti, C., Connor, R. C., Fordyce, R. E., Herman, L. M., ...Whitehead, H. (2008). A search in claim of evidence: Reply to Manger's thermogenesis hypothesis of brain structure. Biological Reviews, 83, 417-440.

Markowitz, T. M. (2004). Social organization of the New Zealand dusky dolphin (Unpublished doctoral dissertation). Texas A \& M University, College Station, TX. 
Noë, R. (2006). Digging for the roots of trade. In P. Kappeler \& C. P. van Schaik (Eds.), Cooperation in primates and humans: Mechanisms and evolution (pp. 233-262). New York: Springer Verlag.

Odling-Smee, F. J., Laland, K. N., \& Feldman, M. W. (2003). Niche construction: A neglected process in evolution. Princeton, NJ: Princeton University Press.

Owren, M. J., \& Rendall, D. (1997). An affect conditioning model of non-human primate vocalizations. In D.W. Owings, M. D. Beecher, \& N. S. Thompson (Eds.). Perspectives in ethology (Vol. 12: Communication) (pp. 299-346). New York: Plenum Press.

Owren, M. J., \& Rendall, D. (2001). Sound on the rebound: Returning function to the forefront in understanding nonhuman primate vocal signaling. Evolutionary Anthropology, 10, 58-71.

Pack, A. A., \& Herman, L. M. (2007). The dolphin's (Tursiops truncatus) understanding of human gaze and pointing: Knowing what and where. Journal of Comparative Psychology, 12, 34-35.

Pellis, S., \& Pellis, V. (2009). The playful brain: Venturing to the limits of neuroscience. London, UK: OneWorld.

Perry, S., Barrett, H. C., \& Manson, J. H. (2004). White-faced capuchin monkeys show triadic awareness in their choice of allies. Animal Behaviour, 67, 165-170.

Petrie, K. J., Pennebaker, J. W., \& Sivertsen, B. (2008). Things we said today: A linguistic analysis of the Beatles. Psychology of Aesthetics, Creativity, and the Arts, 2, 197-202.

Pfeifer, R., \& Bongard, J. (2007). How the body shapes the way we think. Cambridge, MA: MIT Press.

Pfeifer, R., \& Scheier, C. (1999). Understanding intelligence. Cambridge, MA: MIT Press.

Premack, D., \& Woodruff, G. (1978). Does the chimpanzee have a theory of mind? Behavioral and Brain Sciences, $1,515-526$.

Rauch, A. (2001). Cetacean culture: Resisting myths and adding resonance. Behavioral and Brain Sciences, 24, 352353.

Reader, S. M., \& Laland, K. N. (2002). Social intelligence, innovation and enhanced brain size in primates. Proceedings of the National Academy of Sciences, USA, 99, 4436-4441.

Reader, S. M., \& Laland, K. N. (2003). Animal innovation. Oxford, UK: Oxford University Press.

Reiss, D., \& Marino, L. (2001). Self-recognition in the bottlenose dolphin: A case of cognitive convergence. Proceedings of the National Academy of Sciences, USA, 98, 5937-5942.

Rendall, D. (2004). "Recognizing" kin: Mechanisms, media, minds, modules and muddles. In B. Chapais \& C. Berman (Eds.), Kinship and behaviour in primates. (pp. 295-316). Oxford, UK: Oxford University Press.

Rendall, D., Notman, H., \& Vokey, J. R. (2008). Quotidian cognition and the human-nonhuman divide: Just more or less of a good thing? Behavioral and Brain Sciences, 31, 144-145.

Rendell, L., \& Whitehead, H. (2001). Culture in whales and dolphins. Behavioral and Brain Sciences, 24, 309-382.

Richards, D., Wolz, J., \& Herman, L. M. (1984). Vocal mimicry of computer generated sounds and vocal labeling of objects by a bottlenose dolphin, Tursiops truncatus. Journal of Comparative Psychology, 98, 10-28.

Ricklefs, R. E., \& Wikelski, M. (2002). The physiology/life history nexus. Trends in Ecology and Evolution, 17, $462-468$.

Rumbaugh, D. M., \& Washburn, D. A. (2003). Intelligence of apes and other rational beings. New Haven, CT: Yale University Press.

Russon, A. E. (2006). Acquisition of complex foraging skills in juvenile and adolescent organutans (Pongo pygmaeus): Developmental influences. Aquatic Mammals, 32, 500-510.

Searle, J. R. (1990). Is the brain a digital computer? Proceeding and Addresses of the American Philosophical Association, 64, 21-37.

Seyfarth, R. M., \& Cheney, D. L. (2013). Affiliation, empathy and the origins of theory of mind. Proceedings of the National Academy of Sciences, USA, 110, 10349-10356.

Shultz, S., \& Dunbar, R. I. M (2007). The evolution of the social brain: Anthropoid primates contrast with other vertebrates. Proceedings of the Royal Society B: Biological Sciences, 274, 2429-2436.

Silk, J. B. (2007). Social components of fitness in primate groups. Science, 317, 1347-1349.

Snowdon, C. (2001). Social processes in communication and cognition in callitrichid monkeys: A review. Animal Cognition, 4, 247-257.

Sol, D. (2009). Revisiting the cognitive buffer hypothesis for the evolution of large brains. Biology Letters, 5, 130133.

Sterelny, K. (2004). Externalism, epistemic artefacts and the extended mind. In R. Schantz (Ed.), The externalist challenge (pp. 239-254). Berlin, Germany: Walter de Gruyter.

Sterelny, K. (2007). Social intelligence, human intelligence and niche construction. Philosophical Transactions of the Royal Society B: Biological Sciences, 362, 719-730.

Strum, S. C. (1982). Agonistic dominance in male baboons: An alternative view. International Journal of 
Primatology, 3, 175-202.

Strum, S. C. (1994). Reconciling aggression and social manipulation as means of competition: 1. Life history perspective. International Journal of Primatology, 15, 739-765.

Suomi, S. J., \& Harlow, H. F. (1975). Effects of differential removal from group on social development of rhesus monkeys. Journal of Child Psychology and Psychiatry, 16, 149-164.

Sutcliffe, A., Dunbar, R., Binder, J., \& Arrow, H. (2012), Relationships and the social brain: Integrating psychological and evolutionary perspectives. British Journal of Psychology, 103, 149-168. doi: 10.1111/j.2044-8295.2011.02061.x

Tomasello, M., Call, J., \& Hare, B. (2003). Chimpanzees versus humans: It's not that simple. Trends in Cognitive Science, 7, 239-240.

Vonk, J., \& Povinelli, D. J. (2006). Similarity and difference in the conceptual systems of primates: The unobservability hypothesis. In E. Wasserman \& T. Zentall (Eds.), Comparative cognition: Experimental explorations of animal intelligence (pp. 363-387). Oxford, UK: Oxford University Press.

Vaughn, R. L., Würsig, B., Shelton, D. S., Timm, L. L., \& Watson, L. A. (2008). Dusky dolphins influence prey accessibility for seabirds in Admiralty Bay, New Zealand. Journal of Mammalogy, 89, 1051-1058.

Weller, D. W. (2009). Predation on marine mammals. In W. F. Perrin., B. Würsig, and J. G. M. Thewissen (Eds.), Encyclopedia of marine mammals (2 $2^{\text {nd }}$ ed). (pp. 923-932). Amsterdam: Academic Press, Elsevier.

Wells, R. S. (2003). Dolphin social complexity: Lessons from long-term study and life history. In F. B. M. de Waal \& P. L. Tyack (Eds.),Animal social complexity: Intelligence, culture and individualized societies (pp. 3256). Cambridge, MA: Harvard University Press.

Wells, R. S., Boness, D. J., \& Rathbun, G. B. (1999). Behavior. In J. E. Reynolds III \& S. A. Rommel (Eds.), Biology of marine mammals (pp. 324-422). Washington, DC: Smithsonian Institution Press.

Whitehead, H., \& Lusseau, D. (2012). Animal social networks as substrate for cultural behavioural diversity. Journal of Theoretical Biology, 294, 19-28.

Whiten, A., \& Byrne, R. W. (1997). Machiavellian intelligence II: Extensions and evaluations (Vol. 2). Cambridge, UK: Cambridge University Press.

Whiten, A., Goodall, J., McGrew, W. C., Nishida, T., Reynolds, V., Sugiyama, Y., ...Boesch, C. (1999) Culture in chimpanzees. Nature, 399, 682-685.

Würsig, B., \& Würsig, M. (1980). Behavior and ecology of the dusky dolphin, Lagenorhynchus obscurus, in the South Atlantic. Fisheries Bulletin, 77, 871-890.

Yurk, H., Barrett-Lennard, L., Ford, J. K. B., \& Matkin, C. O. (2002). Cultural transmission within maternal lineages: Vocal clans in resident killer whales in southern Alaska. Animal Behaviour, 63, 1103-1119. 